10.929980

ORN! $/ T M-11843$

OAK RIDGE NATIONAL

LABORATORY

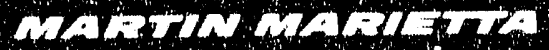

\section{Dispersion Aspects of Silicon Carbide Gelcasting}

A. Bleier 
This report has boefl reproduced directly from the best available copy.

Available to DOE and DOE contractors from the Office of Scientific and Technical Iniormation, P.O. Box 62, Oak Ridge, TN 37831; pricas available from (615) 57 B.8401, FTS $626-8401$.

Available to the public from the National Technical Initormation Service, U.S. Department of Commerce, 5285 Port Hoyal Rd., Springfield, VA 22161.

This report was preparket as an account of work sponsored by an aggnicy of the United States Govemment. Neither the United States Government nor any agency thereot, nor any of their employees, makes any warranty, express or implied, or assumes any legat liability or responsibility for the accuracy, com. pleteness, or usefulnass of any information, apparatus, product, or process dis. closed, or represents that its use would not intringe privately owhed rights. Reference herein to any specific commercial producs, process, or service by trade narne, tradernark, manufactures, or otherwise, does not necessarily consti. tute or irmply its endorsement, recommendation, or favoring by the United States Government or any agency thereot. The views and opinions of authors expressed herein do not necessarily state or retied those of the United States Government or any agancy thereot. 
Metals and Ceramics Division

\section{DISPERSION ASPECTS OF SILICON CARBIDE GELCASTING}

A. Bleier

Date Published: September 1991

NOTICE: This document contains information of a preliminary nature. It is subject to revision or correction and therefore does not represent a final report.

Prepared for Assistant Secretary for Conservation and Renewable Energy Office of Industrial Technologies Industrial Energy Efficiency Division ED 0112000

Prepared by the OAK RIDGE NATICNAL LABORATORY

Oak Ridge, 'Tennessee 37831-6285 managed by MARTIN MARIETTA ENERGY SYSTEMS, INC. for the U.S. DEPARTMENT OF ENERGY under contract DE-AC05-84OR21400 


\section{TABLE OF CONTENTS}

Page

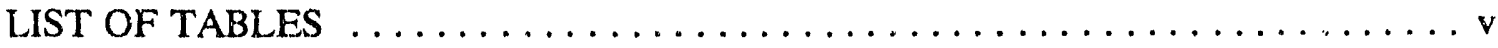

LIST OF FIGURES $\ldots \ldots \ldots \ldots \ldots \ldots \ldots \ldots \ldots \ldots \ldots \ldots \ldots \ldots \ldots \ldots \ldots$

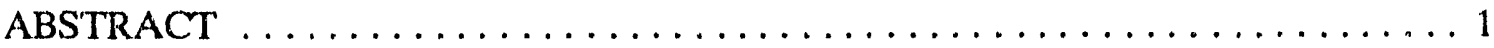

1. INTRODUCTION $\ldots \ldots \ldots \ldots \ldots \ldots \ldots \ldots \ldots \ldots \ldots \ldots \ldots \ldots \ldots \ldots \ldots \ldots$

2. EXPERIMENTAL MATERIALS AND PROCEDURES $\ldots \ldots \ldots \ldots \ldots \ldots \ldots$

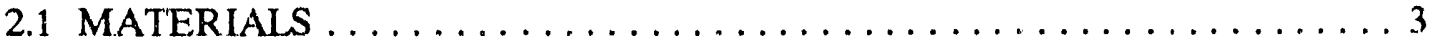

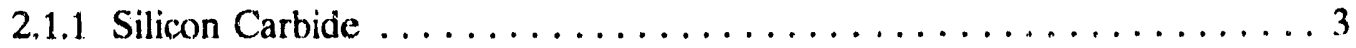

2.1.2 Gelation Chemicals ...................... 4

2.1.3 Other Chemicals ......................... 4

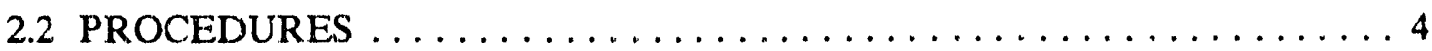

2.2.1 Suspension Properties and Stability $\ldots \ldots \ldots \ldots \ldots \ldots \ldots \ldots \ldots$

2.2 .2 Gelation . . . . . . . . . . . . . . . . . . . 8

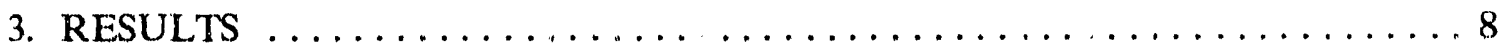

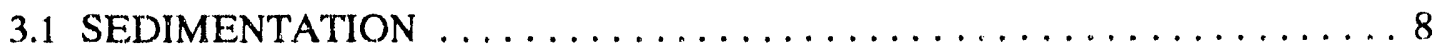

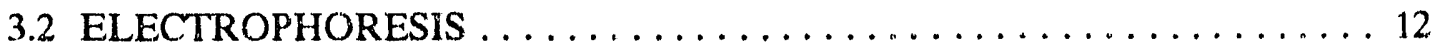

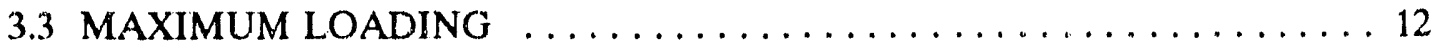

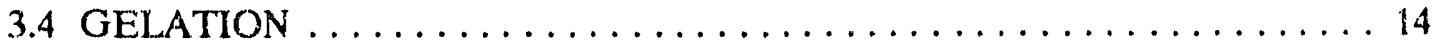

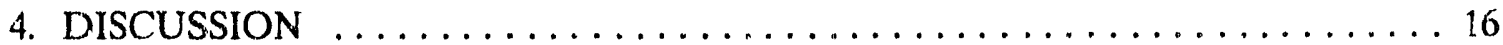

4.1 GENERAL SUSPENSION REQUIREMENTS . . . . . . . . . . . 16

4.2 ROLE OF PARTICLE AND SUSPENSION PROPERTIES . . . . . . . . 16

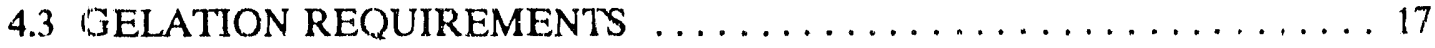

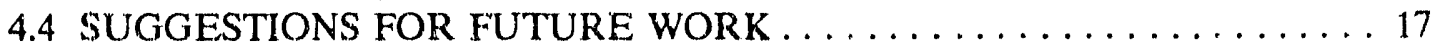

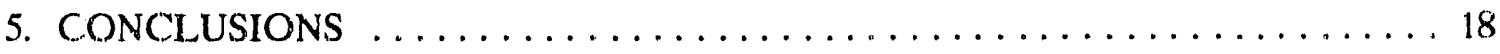

6. ACKNOWLEDGMENTS ......................... 19

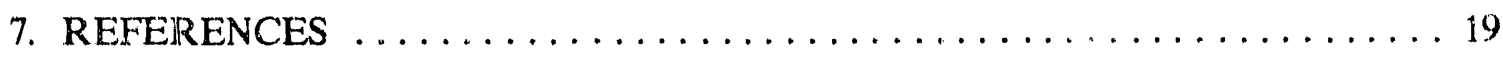




\section{LIST OF TABLES}

Table Page

1 Physical and chemical properties of silicon carbide powders $\ldots \ldots \ldots \ldots \ldots \ldots$

2 Gelation conditions $\ldots \ldots \ldots \ldots \ldots \ldots \ldots \ldots \ldots \ldots \ldots \ldots$

3 Maximum loading of silicon carbide powders $\ldots \ldots \ldots \ldots \ldots \ldots \ldots \ldots \ldots$

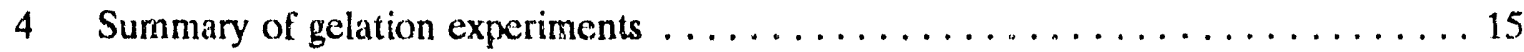




\section{LIST OF FIGURES}

Figure

Page

1 Particle size distributions for: (a) B-10, (b) 377, (c) 375, and $(d) 074$; see Table 1 for values of median diameter $\ldots \ldots \ldots \ldots \ldots$

2 Electrophoretic mobility as a function of $\mathrm{pH}$ for each powder in Table 1. Electrical conductivity data indicate that the ionic strength is on the order of $0.01 \mathrm{~mol} \mathrm{dm}^{-3}$ .7

3 Sedimentation behavior of suspensions containing: (a) B-10, (b) $377,(c) 375$, and (d) 074 , represented in terms of the relative sedimentation height (RSH) as a function of $\mathrm{pH}$ for selected ages. Relative packing density ( $\mathrm{vol} \%$ ) is obtained by multiplying the initial concentration by the term, $1 /$ RSH $\ldots \ldots \ldots \ldots \ldots \ldots \ldots$

4 Maximum loading (vol \%) for $\mathrm{B}-10$ as a function of $\mathrm{pH}$. Closed squares represent suspensions prepared in the presence of gelation reagents; open square denotes the absence of these components. "Pourable" and "Nonpourable" refer to the rheology in each regime. See text for additional details 


\title{
DISPERSION ASPECTS OF SILICON CARBIDE GELCASTING*
}

\author{
A. Bleier
}

\begin{abstract}
The principal objective of this research was to increase the solid loading of silicon carbide ( $\mathrm{SiC}$ ) powder, in an appropriate liquid medium, to a level that is useful for gelcasting technology. A number of factors that determine the maximum concentration of silicon carbide that can be incorporated into a pourable ceramic suspension have been identified. The $\mathrm{pH}$ of the system is the most critical processing parameter. Its proper adjustment ( $\mathrm{pH} 11$ to 13) allows $\mathrm{SiC}$ concentrations exceeding $50 \%$, based on volume, to be routinely achieved without the use of additional dispersing agents. The particle size of $\mathrm{SiC}$ was also found to affect the maximum, attainable concentration. The surface area of the powder and the presence of free carbon in the powder, though not significantly influencing the suspension properties, determine the concentration of initiator required to induce polymerization and gelation. $\mathrm{SiC}$ specimens have been gelcast for powders in the size range of 0.8 to $8.5 \mu \mathrm{m}$; the powders employed contain either $\sim 0$ or $19 \%$ carbon by weight. Finally, the generation of bubbles, typically encountered by the use of ammonia to adjust $\mathrm{pH}$, has been circumvented by the use of tetramethylammonium hydroxide.
\end{abstract}

\section{INTRODUCTION}

The traditional fabrication of ceramic parts is limited to several forming procedures such as pressing, slip casting, and injection molding. Although each technique possesses individual merits, there is evidence that none of them is capable of facing today's challenges alone. ${ }^{1,2}$ Recently, a unique, near-net-shape forming technology named "gelcasting" has been developed at Oak Ridge National Laboratory (ORNL). ${ }^{2}$ This generic method of fabricating ceramic bodies utilizes in situ polymerization of acrylamide, in the presence of a crosslinking agent,

"Research sponsored by the U.S. Department of Energy, Assistant Secretary for Conservation and Renewable Energy, Office of Industrial Technologies, Industrial Energy Efficiency Division, under contract DE-AC05-84OR21400 with Martin Marietta Energy Systems, Inc. 
that induces gelation of a slurry containing a high content of ceramic powder. The potential impact of this process is that complex, near-net shapes can be optimally fabricated.

This project utilizes the gelcasting technology to produce ceramic parts that can be used in advanced industrial heat exchanger systems. Silicon carbide is a candidate material for these applications. However, the processing of its aqueous suspensions has been a pressing issue. ${ }^{3}$ Specific processing problems relate to the tendency of $\mathrm{SiC}$ particulates to cluster and to form agglomerates held together by strong van der Waals forces. These clusters (1) limit the maximum concentration of solid that can be incorporated into a ceramic slurry and (2) generate large voids when the powder is consolidated. The maximum concentration of SiC that can be achieved in a slurry is characterized by the particle concentration limit that induces a prohibitively high suspension viscosity, making the slurry nonpourable and paste-like. In the past, this situation nas been found to occur within the range of 20 to $30 \mathrm{vol} \% \mathrm{SiC}^{3,4}$ Preliminary research ${ }^{3 a}$ focused on identifying a suitable dispersant that would adsorb at the particle surface and establish a barrier that prevents neighboring, suspended particles from closely approaching each other and forming the clusters that render a slurry nonpourable. Such an approach would permit significantly more SiC to be dispersed. However, this prior research failed to identify a suitable candidate dispersant that allows $\mathrm{SiC}$ concentrations excecding -37 vol $\%$. $^{3 a}$

The major objectives of the present research were to increase the maximum concentration of $\mathrm{SiC}$ significantly and to identify suitable dispersants, if needed. A secondary set of objectives was to minimize or to eliminate the problem of foaming, eaused by the presence of ammonia used previously to adjust suspension $\mathrm{pH}$, and to elucidate the role of impurities in the powder. For each set of objectives, the effect of suspension pH is of major concern. Particles of $\mathrm{SiC}$ interact with an aqueous solution and establish a surface charge that, if of sufficiently large magnitude, effectively counteracts the van der Waals forces that promote clustering, thereby providing electrostatic stabilization. This surface interaction and the resultant surface charge depend on the $\mathrm{pH}$. Moreover, the magnitude of surface charge and the $\mathrm{pH}$ can greatly influence the adsorption of dispersants and thus control whether or not these additives are effective. The problem of foaming stems from the common use of ammonia te control the suspension pH. Since the partial pressure of ammonia gas depends on $\mathrm{pH}$, the nucleation of bubbles is aiso $\mathrm{pH}$-sensitive. Lastly, impurities often dominate the colloidal properties of a suspension if they either concentrate at the particle surface or exist as solids that also disperse when $\mathrm{SiC}$ powder is processed. In each case, their influence is usually 
sensitive, in part, to $\mathrm{pH}$ for the reasons just explained for SiC. The possibilities that freecarbon particles might be present in the powders and that a free-carbon coating may exist on the $\mathrm{SiC}$ particles were not directly investigated.

\section{EXPERIMENTAL MATERIAIS AND PROCEDURES}

\section{MATERIALS}

\subsubsection{Silicon Carbide}

Table 1 summarizes selected physical and chemical properties of the powders examined. Values of the median diameter were obtained by analyzing particle size distributions obtained

Table 1. Physical and chemical propertics of silicon carbide powders

\begin{tabular}{|c|c|c|c|c|}
\hline \multirow{2}{*}{ Property } & \multicolumn{4}{|c|}{ Characteristics } \\
\hline & Starck $^{a}$ & & r Grap & \\
\hline Designation & B-10 & 377 & 375 & 074 \\
\hline $\begin{array}{l}\text { Typical composition } \\
\text { Silicon Carbide, wt. } \% \\
\text { Free carbon, wt } \%{ }^{c} \\
\text { Oxygen, wi } \%\end{array}$ & $\begin{array}{r}97.5 \\
<0.5 \\
1.1\end{array}$ & $\begin{array}{r}80.5 \\
18.5 \\
0.6\end{array}$ & $\begin{array}{r}80.5 \\
18.5 \\
0.6\end{array}$ & $\begin{array}{l}98.5 \\
0.6 \\
0.6\end{array}$ \\
\hline Density, $\mathrm{g} \mathrm{cm}^{-3}$ & 3.10 & 3.10 & 3.10 & 3.10 \\
\hline Surface area, $\mathrm{m}^{2} \mathrm{~g}^{-1}$ & 12.85 & 5.14 & 3.37 & $1-2^{4}$ \\
\hline Median diameter, $\mu \mathrm{m}$ & 0.85 & 1.7 & 8.5 & 2.9 \\
\hline Isoelectric point, $\mathrm{pH}_{\text {iep }}$ & 2.9 & 3.2 & 2.9 & 3.0 \\
\hline
\end{tabular}

${ }^{a}$ Hermann C. Starck, Berlin.

${ }^{b}$ Superior Graphite Co., Chicago, Ill.

Terminology of supplier; the physical form of free carbon is not evident and may be, as examples, particulate carbon (a coating of carbon on the silicon carbide) and excess, nonstoichiometric carbon in the silicon carbide.

${ }^{d}$ HSC 074, 075, 077 Silicon Carbide (Beta Phase) [product data sheet], Superior Graphite Co., Chicago, September 18, 1989. 
from sedimentation data (see Fig. 1). The specific surface area was measured by gas adsorption, and the isoelectric point was determined electrophuretically as described later.

The crystallographic phase of each powder was determined by its supplier. ${ }^{5.7}$ 'The powders in Table 1 contain free carbon, whose relative concentration varies from source to source. The concentration of carbon in a suspension is related to that of $\mathrm{SiC}$ and is typically $<1$ to $18.5 \mathrm{wt} \%$, depending on which powder is used. The relative concentration of oxygen also varies slightly from source to source, being on the order of $1.0 \mathrm{wt} \%$.

\subsection{Gelation Chemicals}

The components of the gelcasting process are the same as those recently described for alumina ceramics by Young et al. ${ }^{2}$ These reagents are (1) the acrylanide monomer $\left[\mathrm{CH}_{2}=\mathrm{CHCONH}_{2}\right] ;(2) \mathrm{N}, \mathrm{N}^{\prime}$-methylene bisacrylamide $\left[\left(\mathrm{CH}_{2}=\mathrm{CHCONH}\right)_{2} \mathrm{CH}_{2}\right]$, the crosslinking agent; and (3) ammonium persulfate, $\left[\left(\mathrm{NH}_{4}\right)_{2} \mathrm{~S}_{2} \mathrm{O}_{8}\right]$, the free-radical initiator for this system.

\subsubsection{Other Chemicals}

Hydrochloric acid and tetramethylammonium hydroxide (TMAOH), $\left(\mathrm{CH}_{3}\right)_{4} \mathrm{~N}^{+} \mathrm{OH}$, were used to adjust $\mathrm{pH}$. TMAOH was chosen because it is nonvolatile and decomposes on heating to trimethylamine and methanol, ${ }^{8}$ which are easily removed during subsequent processing stages. Finally, distilled, deionized water was used in all experiments.

\subsection{PROCEDURES}

\subsubsection{Suspension Properties and Stability}

Relative suspension or sedimentation height (RSH) was evaluated at desired times up to two weeks after sample preparation and represents the effect of gravity on the particulates in the suspension. This measurement was conducted using quiescent suspensions in which the volumebased coneentration of $\mathrm{SiC}$ was initially either 5.0 or $8.2 \%$, and the $\mathrm{pH}$ was in the range of 2 to 12 .

For this evaluation, the height of the demarcation between the turbid, lower region in a solution-powder mixture that contains the settling particulates and the clear, upper region that is essentially free of them is measured and normalized to the overall height of the sample. Cylindrical containers were used to ensure that height of the suspension phase is proportional

\footnotetext{
"Centrifugal Particle Size Analyzer, Model 50), Horiba Instruments, Inc., Irvine, Calif.
} 
ORNL-DWG 91Z-11119

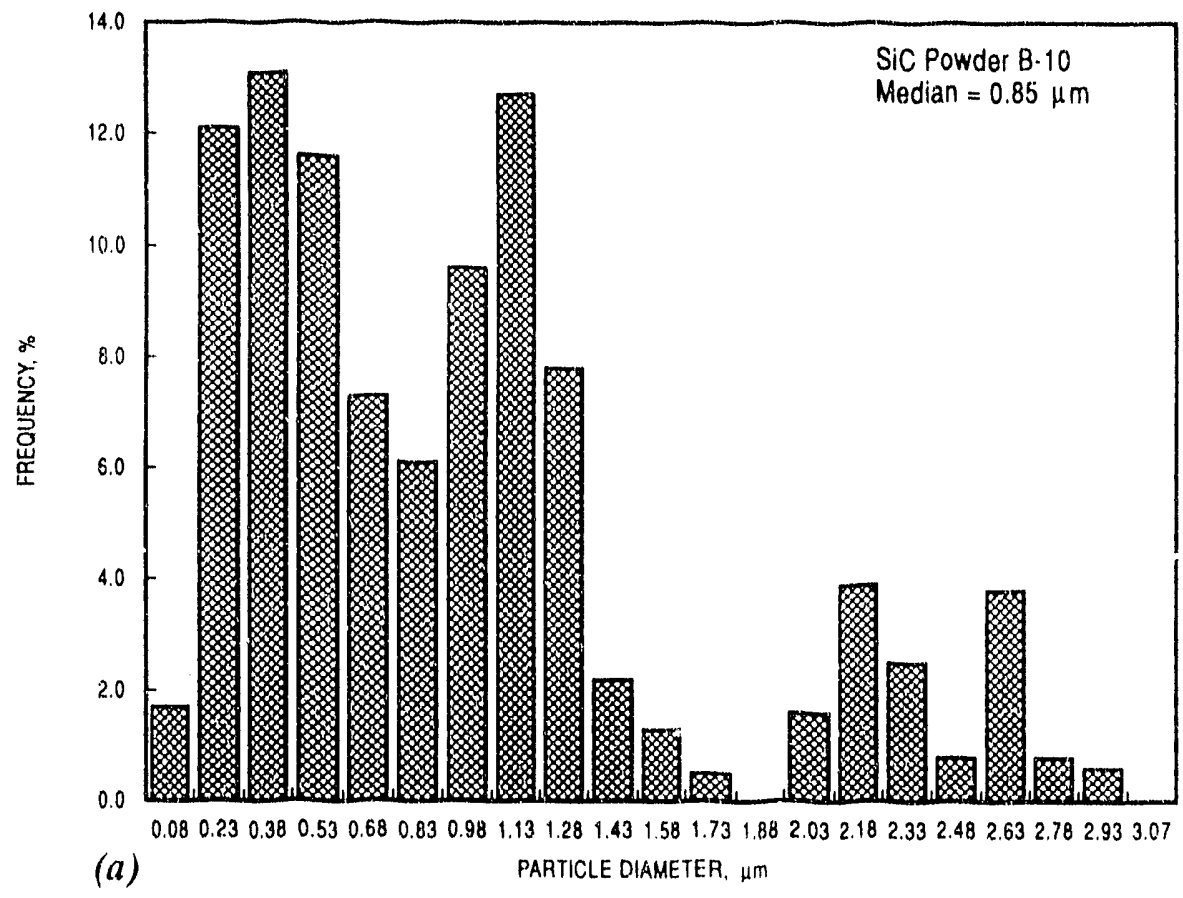

ORNL-DWG 91Z-11120

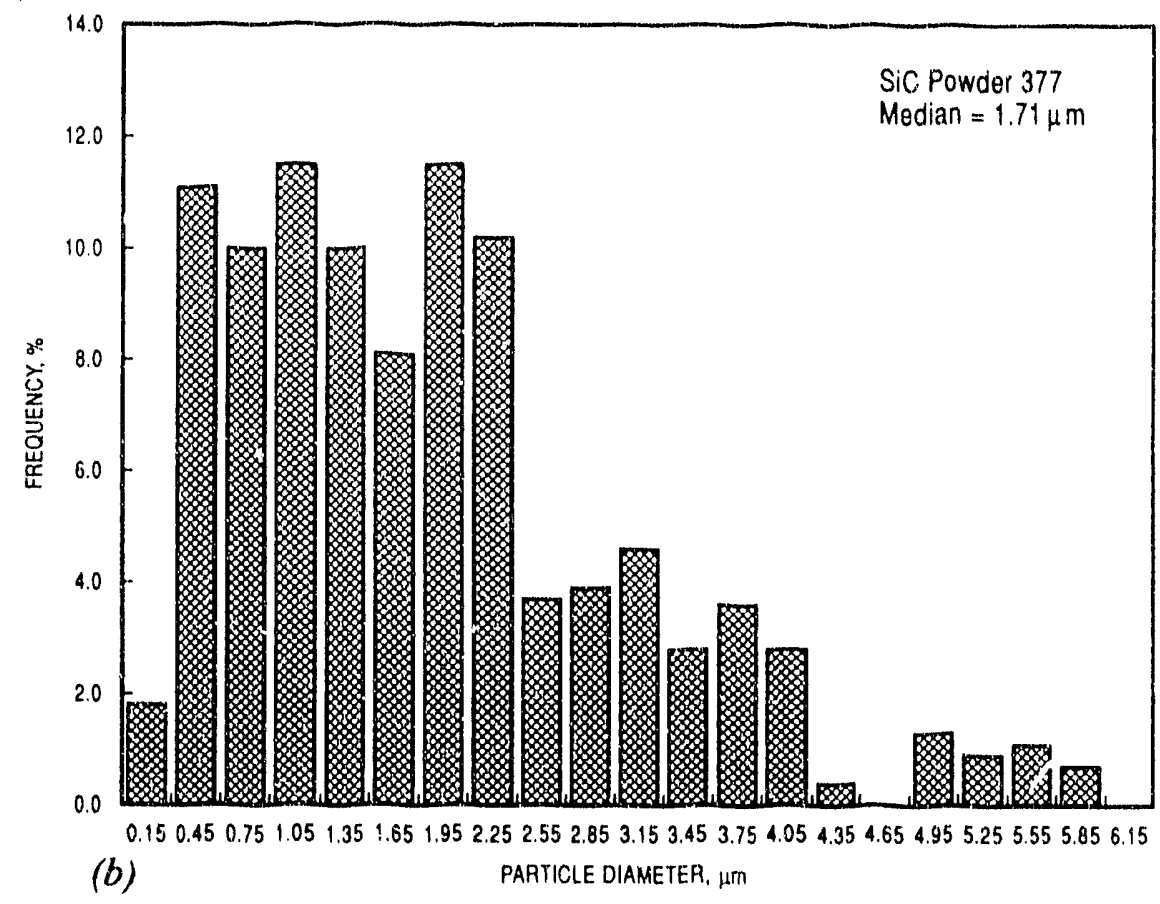

Fig. 1. Particle size distributions for: (a) B-10, (b) 377, (c) 375 , and $(d) 074$; see Table 1 for values of median diameter. 
ORNL-DWG 91Z-11121

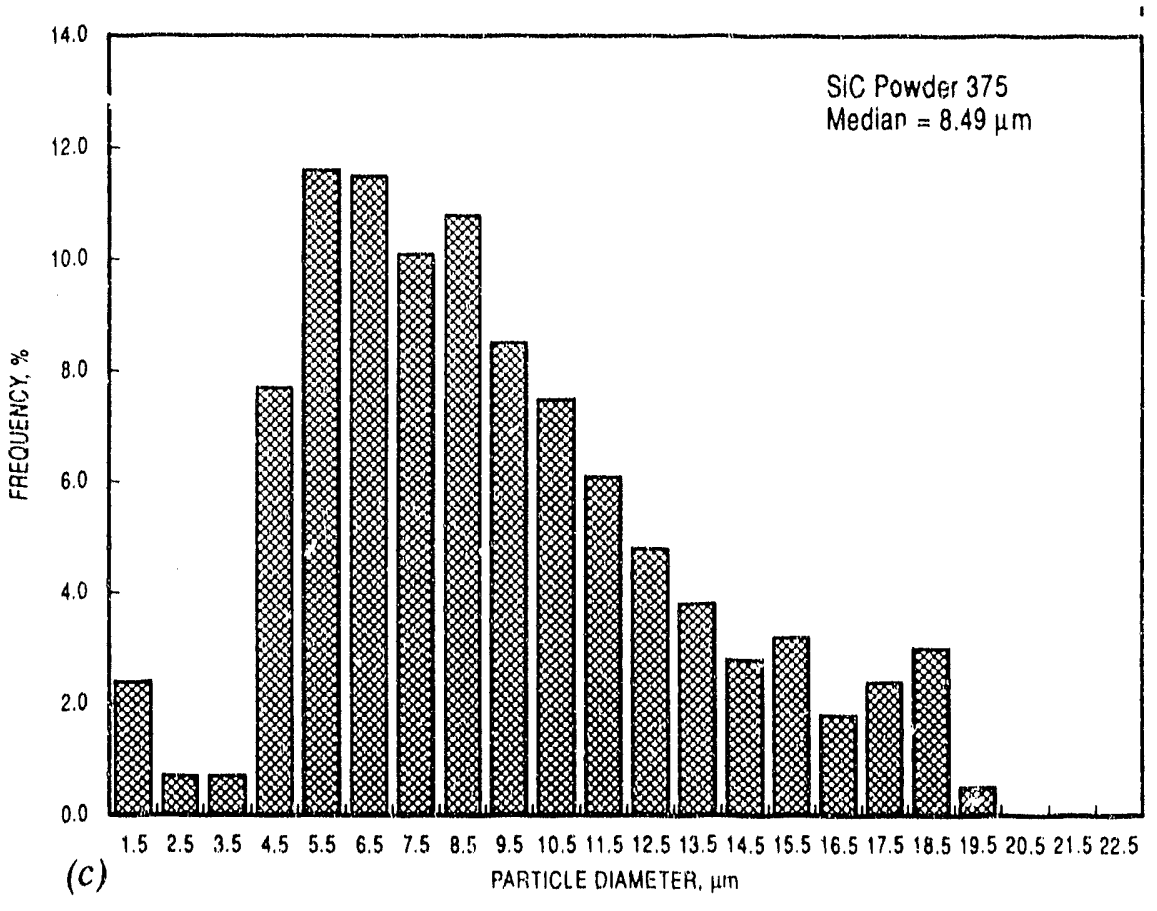

ORNL.DWG 91Z-11122.

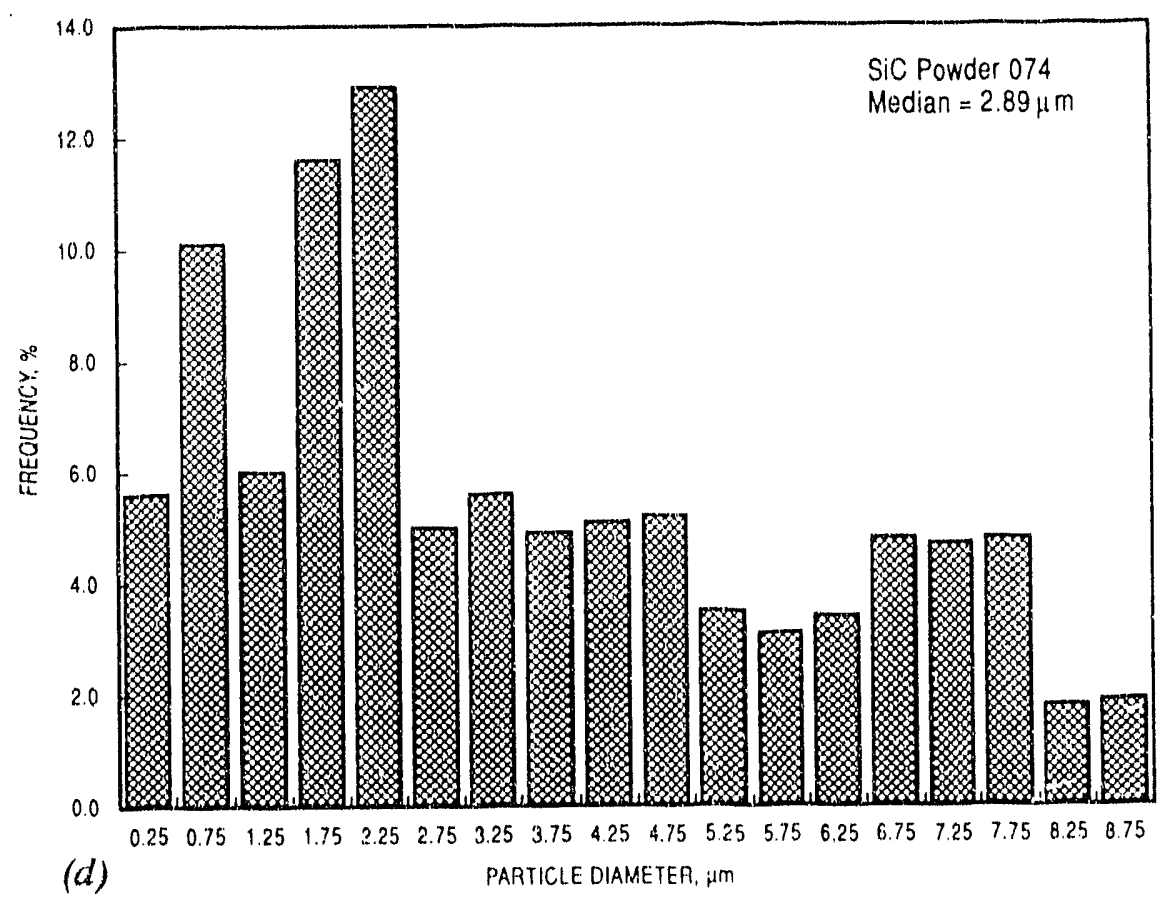

Fig. 1. continued. 
to its volume. Thus, the term, 1/RSH, represents the degrce to which a suspension is concentrated during gravitational sedimentation. At short times, RSH values near unity indicate that virtually no settling has occurred and that the suspension is colloidally stable. Low RSH values, on the other hand, denote colloidally unstable systems because particulate clusters settle faster than their component primary particles.

At long times, however, the relationship between stability and RSH is rerersed. That is, colloidally stable systems form sediments possessing a high-volume fraction of solid, owing to efficient packing of the particulates that often approaches the maximum, attainable consolidation. These systems now exhibit low RSH values. Unstable ones now contain clusters that do not pack efficiently and, therefore, have higher RSH values at extended age.

Electrophoretic mobility, $\mu_{\mathrm{E}}$, was ucasured at $25^{\circ} \mathrm{C}$ using an automated analyzer to determine the $\mathrm{pH}$-sensitivity of the surface charge responsitle for the stability phenomena. Small samples of the concentratud suspensions were diluted with aqueous solution corresponding to the desired $\mathrm{pH}$ and subjected to ultrasonication prior to measurement.

Figure 2 summarizes the electrophoretic mobility data for the powders in Table 1. Though small differences exist among the powders, they exhibit similar behavior.

ORNL-DWG 91Z-11123

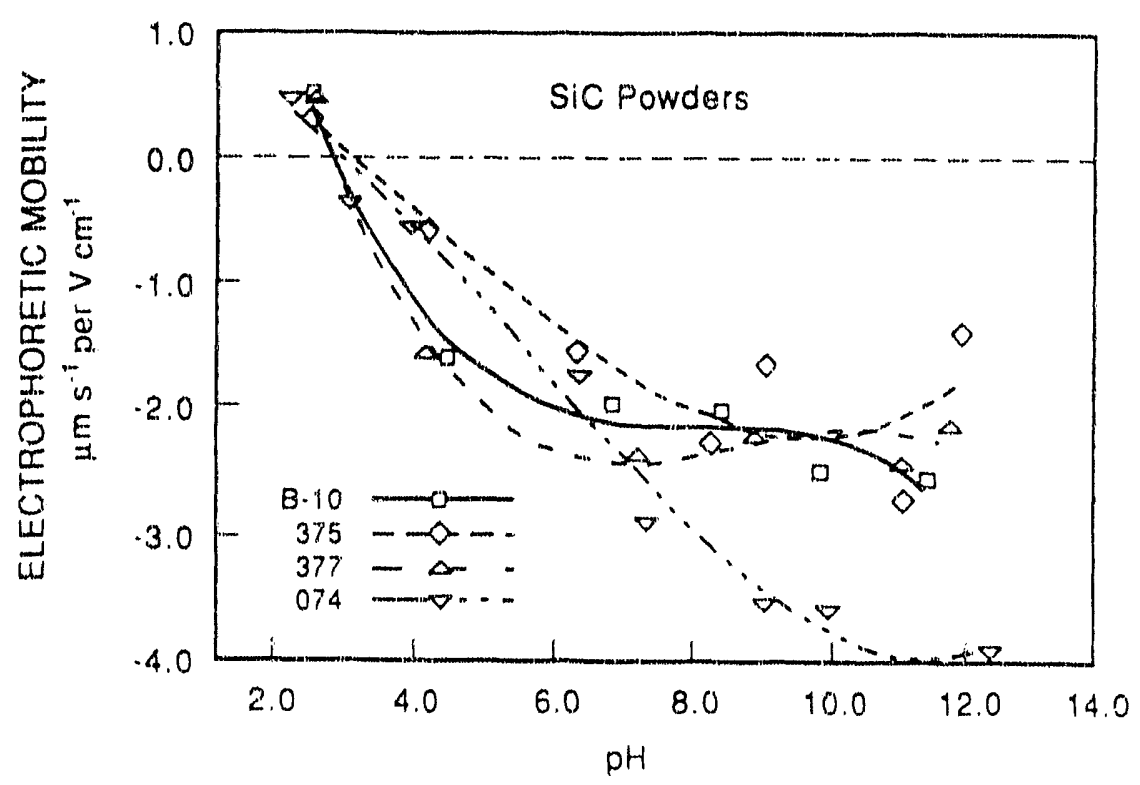

Fig. 2. Electrophoretic mobility as a function of $\mathrm{pH}$ for each powder in Table 1. Electrical conductivity data indicate that the ionic strength is on the order of $0.01 \mathrm{~mol} \mathrm{dm}^{-3}$. 
That is: (a) each possesses an isoelectric point near pH 3, a condition for which more acidic systems $(\mathrm{pH}<3)$ are positively charged and more basic ones $(\mathrm{pH}>3)$ are negatively charged; and (b) they each attain maximum surface charge, as reflected by $\mu_{E}$-values, in the vicinity of $\mathrm{pH} 7.5$ and at higher values.

Lastly, the maximum concentration of $\mathrm{SiC}$ that can be dispersed, while maintaining sufficient fluidity to ensure that the suspension is pourable, was determined by incorporating increasing amounts of powder into a suspension until its rheological properties qualitatively suggested the onset of prohibitively high viscosity and thixotropy. The highest concentration of $\mathrm{SiC}$ for which the suspension could be poured is denoted as the maximum loading. This property was evaluated under selecled $\mathrm{pH}$ conditions.

\section{Gelation}

Selected concentrated suspensions $(-50 \mathrm{vol} \% \mathrm{SiC})$ were prepared in the $\mathrm{pH}$ range of 10.7 to 13.1 and in the presence of monomer. crosslinking agent, and initiator. These suspensions were cast i.. polypropylene bottles and placed for $1 \mathrm{~h}$ in an oven that had been preheated to $600^{\circ} \mathrm{C}$; each contained 20 to $25 \mathrm{~g} \mathrm{SiC}$. The gelation conditions a a summarized in Table 2. The scope of these experiments is limited and principally focuses on powder B-10.

Table 2. Gelation conditions

\begin{tabular}{lccc}
\multicolumn{3}{c}{$\mathrm{pH}$} & \multicolumn{3}{c}{$\begin{array}{c}\text { Concentrations in solutions } \\
(\mathrm{wt} \%)\end{array}$} \\
\cline { 2 - 4 } & Monomer & Crosslinking agent & Initiator \\
\hline 10.7 to 13.1 & $12^{c}$ & $0.52^{b}, 1.02^{c}$ & $0.2,0.4,0.8,1.6$
\end{tabular}

${ }^{a}$ Average for the range, 10.2 to $12.6 \mathrm{wt} \%$.

${ }^{b}$ Average for the range, 0.44 to $0.54 \mathrm{wt} \%$.

${ }^{c}$ Average for the range, 0.98 to 1.07 wt $\%$.

\section{RESULTS}

\subsection{SEDIMENTATION}

Figure 3 summarizes the sedimentation data for the powders in 'lable 1. The behaviors of B-10, 375, and 074, expressed as functions of pH in Figs. 3(a), (c), and (c), 
ORNL-DWG 91Z-11124
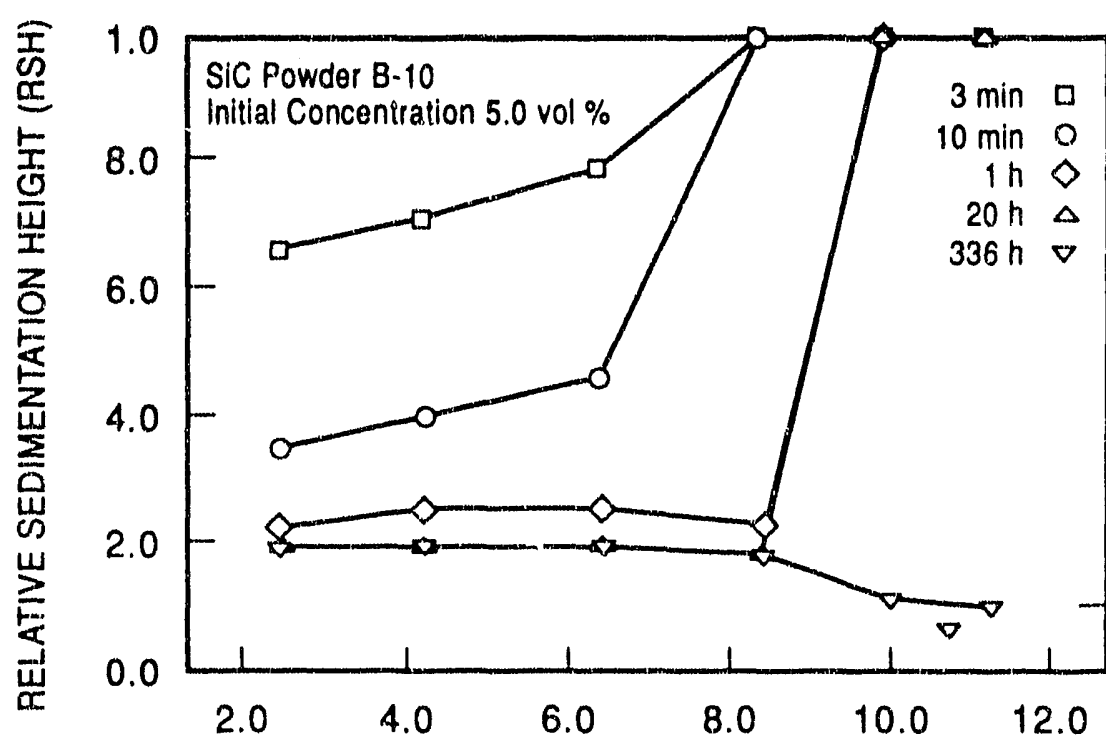

50 岕

(a)

$\mathrm{pH}$

ORNL-DWG 91Z-11125

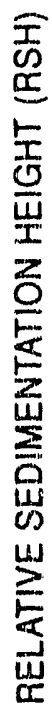

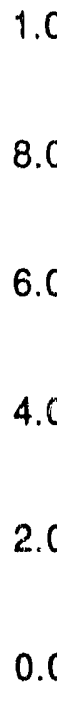

1.0
6.0
4.0
0.0
0.0

(b)
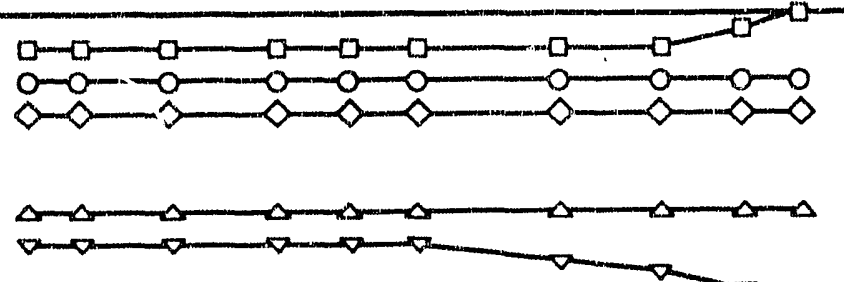

$\stackrel{\circ}{\circ}$

8.0

4.0

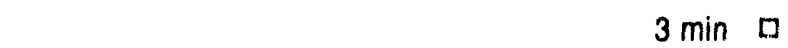

$10 \min 0$

$0.5 \mathrm{~h} \theta$

in $\Delta$

SiC Powder 377

Initial Concentration 5.0 vol \%

$20 \mathrm{~h} \nabla$

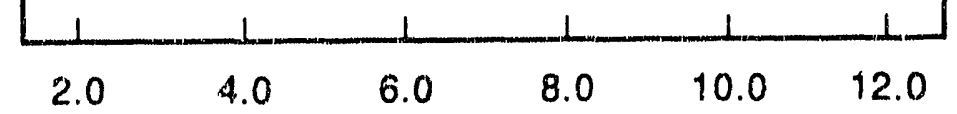

2.0

Fig. 3. Sedimentation behavior of suspensions containing: (a) B-10, (b) 377 , (c) 375 , and (d) 074, represented in terms of the relative sedimentation height (RSH) as a function of $\mathrm{pH}$ for selected ages. Relative packing density (vol \%) is obtained by multiplying the initial concentration by the term, $1 /$ RSH. 
ORNL-DWG 91Z-11126

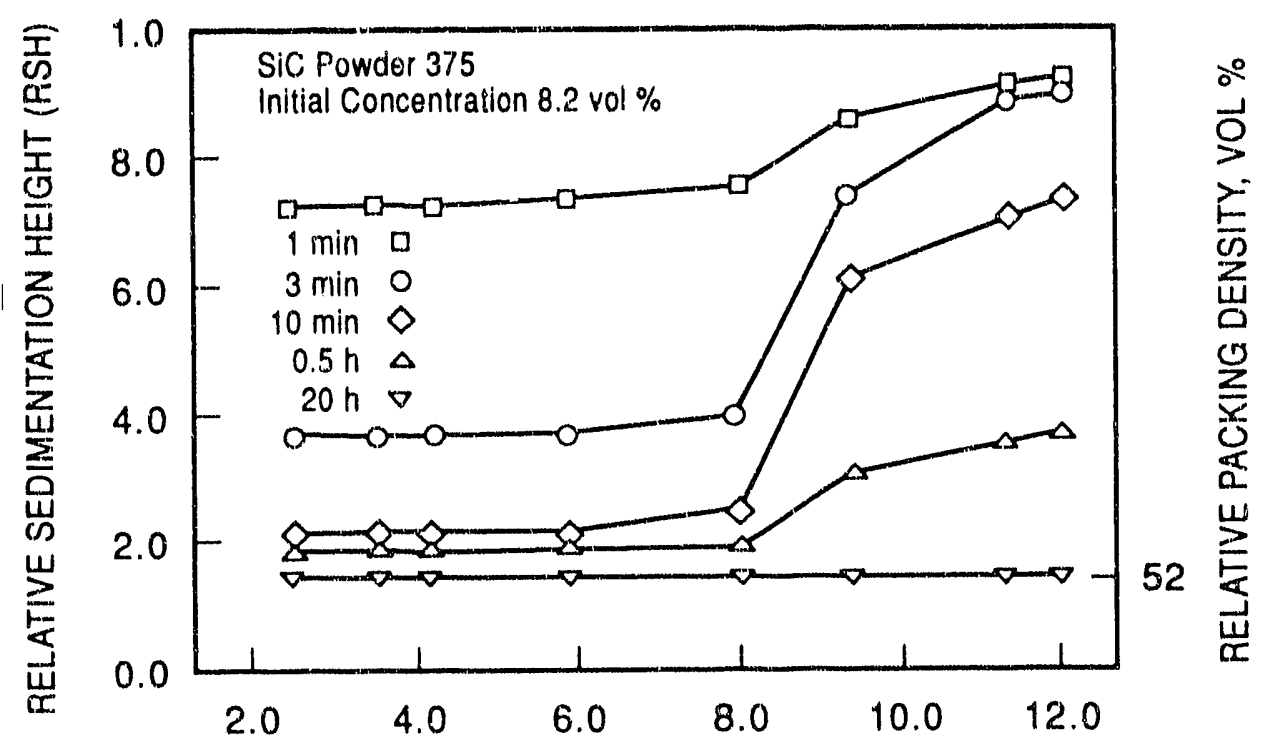

(c)

pH

ORNL-DWG 91Z-11127

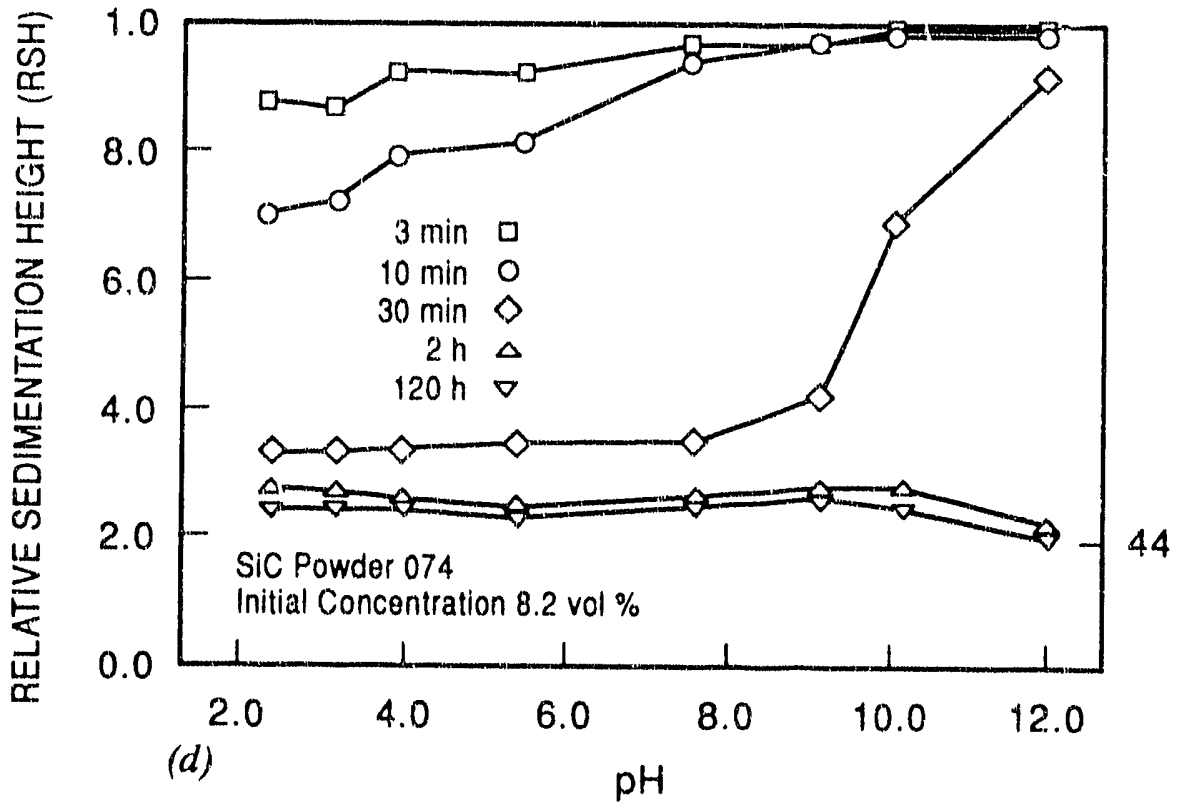

Fig. 3. continued. 
respectively, are qualitatively similar. Using B-10 as an example, the data in Fig. 3(a) indicate that, for aging times of 3 and $10 \mathrm{~min}, \mathrm{pH}$ conditions $\sim 8.4$ and higher promote stability (i.e., high RSH values that reflect limited settling of $\mathrm{SiC}$ ). After $1 \mathrm{~h}$, suspensions require at least $\mathrm{pH} 10$ to be stable. The data indicate colloidal stability exists above $\mathrm{pH} 10$ and is independent of time. The fact that systems which stay suspended the longest also pack most efficiently, yielding low D.SH values after long aging times, underscores the high degree of colloidal stability established under these basic conditions.

Figures $3(c)$ and $(d)$, respectively, show that 375 and 074 behave similarly, although the particle size of the first power is an order of magnitude greater than that of B-10, and that of the second power is approximately 3.5 times larger than B-10. Note that 375 and 074 settle more rapidly than $\mathrm{B}-10$, even at high $\mathrm{pH}$. The small reductions in $\mathrm{RSH}$ for long aging times, under $\mathrm{pH}$ conditions more basic than 8 to 9.5 for 375 and $\mathrm{pH} 10$ for 074 , indicate a slightly increased packing density in these regimes.

Figure $3(b)$, in contrast to Figs. $3(a),(c)$, and $(d)$, indicates that the sedimentation behavior of 377 is quite different from that just described for B-10, 375, and 074. The rate of sedimentation in this case is quite low, indicating that the suspended state exists for at least $20 \mathrm{~h}$ and is essentially independent of $\mathrm{pH}$. The maximum, relative packing density obtained with 377 is $\sim 9 \%$. This value significantly differs from those of B-10, 375, and 074, whose approximate values are 50,52 , and $44 \%$, respectively. The very different behavior of 377 surgests that this powder forms a flocculated network that does not easily collapse under its own weight. Presently, the reasons for this behavior are unclear. However, since the 3-min and 20-h data suggest an increased stability above $\mathrm{pH} 10$ to 11 , the degree of which is significantly less than those suggested earlier, the processing of this powder may banefit from the use of dispersants.

Summarizing the sedimentation data contained in Fig. 3 and neglecting the behavior of 377 , the powders exhibit pH-dependent colloidal stability, with the basic conditions above $\mathrm{pH} \sim 10$ being generally more suitable for preparing concentrated suspensions. The trends in relative packing density demonstrate this point clearly. The only effect detected in the sedimentation experiments, which is uniquely attributable to particle size, is that of an increased settling rate with increasing median diameter. The consequence of this phenomenon is that the minimum $\mathrm{pH}$ for stability increases slightly as larger particle sizes are considered; see Figs. $3(a)[0.85 \mu \mathrm{m}], 4(c)[8.49 \mu \mathrm{m}]$, and $(d)[2.89 \mu \mathrm{m}]$. 


\subsection{ELECTROPHORESIS}

The data in Fig. 2, as described earlier, demonstrate that many similarities exist among the powders listed in Table 1. Of particular importance is the location of the isoelectric point $\left(\mathrm{pH}_{\text {iep }}\right)$ at which $\mu_{\mathrm{E}}$ is zero. The $\mathrm{pH}_{\text {iep }}$ value of each powder is given in Table 1. As indicated in Fig. 2, this electrophoretic condition occurs under identical $\mathrm{pH}$ conditions $(\mathrm{pH}-3)$ for each powder, suggesting that they are fundamentally the same with respect to the acidic and basic sites, which control surface charge, and that the difference in oxygen content for B-10 is insignificant in this regard. In fact, the isoelectric conditions of these SiC powders remarkably resemble those studied by Whitman and Feke. ${ }^{9}$ Washing of the powders may lower the $\mathrm{pH}_{\text {iep }}$ to $\sim 2.5$ by removing soluble acidic species, ${ }^{10}$ but this procedure was not investigated.

However, as was also stated earlier, the profiles for B-10 and 377 resemble one another and differ from those of the other two powders by initially establishing a moderately high surface charge near $\mathrm{pH} \mathrm{4}$, as indicated by their $\mu_{\mathrm{E}}$ values. Contrasting this behavior is that of powders 375 and 074 , which require $\mathrm{pH} 6$ to establish a similar magnitude of charge.

However, 074 develops a much greater electrophoretic mobility (surface charge) at higher $\mathrm{pH}$, as compared to the other powders.

The preceding data suggest that the presence of free carbon reduces the maximum attainable concentration of charged surface sites. If this statement is valid, electrophoretic data for washed (e.g., soxhelated) powders, presently unavailable, would help to clarify the impact of free carbon on the processing of these powders and possibly its physical form. If such data demonstrate an increased electrophoretic mobility following soxhelation, the soluble component may chemically be considered as oxidized carbon. Its concentration would then be estimated from the difference in mobility profiles brought on by the washing process. Of course, powder 074 , which contains little free carbon, should be virtually unaffected by this procedure.

\subsection{MAXIMUM LOADING}

Figure 4 summarizes the data gathered for B-10. A critical pH-sensitivity is evident in this figure. When $\mathrm{pH}<10$, maximum loading corresponds to suspensions that are too dilute for typical gelcasting considerations. On the other hand, when $\mathrm{pH}>11$, values of maximum loading that exceed $50 \%$ are achieved, approaching a relatively $\mathrm{pH}$-independent value of $-53 \%$ when $\mathrm{pH} \geq 11.5$.

Tabie 3 contains data gathered on each powder in Table 1. The maximum loading of 377 increases with increasing $\mathrm{pH}$, though its greatest value is unacceptable for gelcasting. That of 
ORNL-DWG 91Z-11128

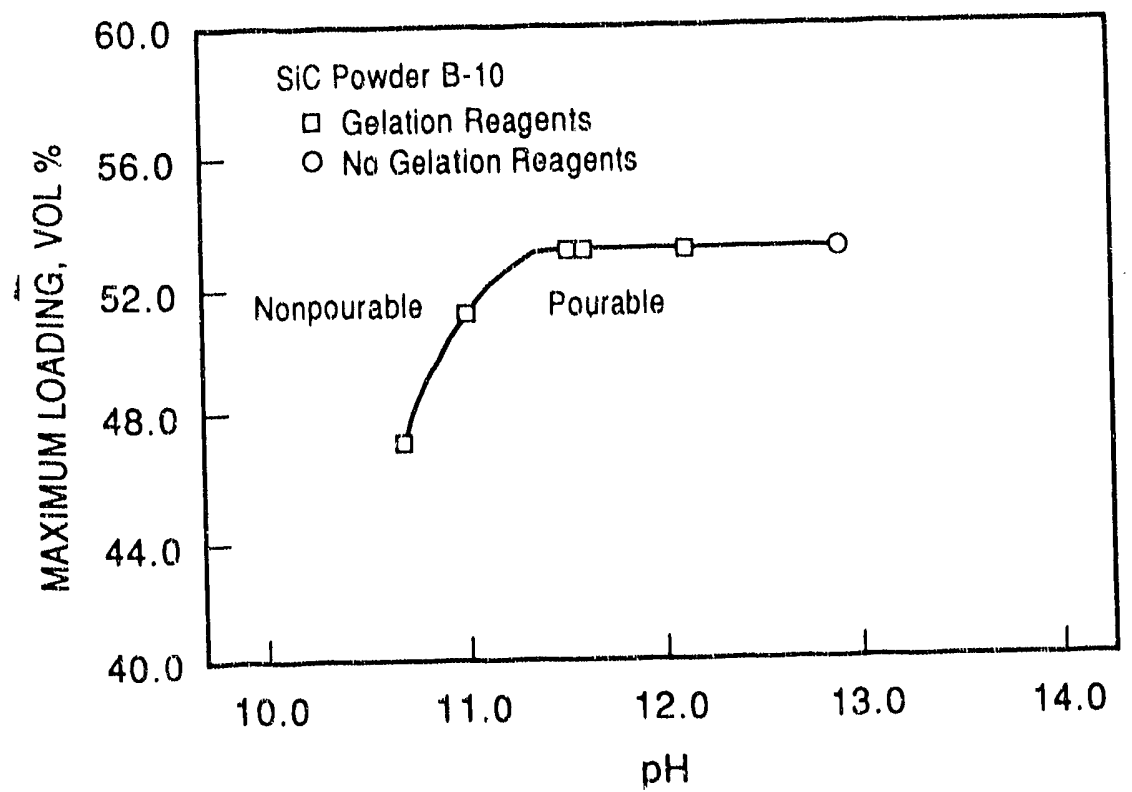

Fig. 4. Maximum loading (vol \%) for B-10 as a function of $\mathrm{pH}$. Closed squares represent suspensions prepared in the presence of gelation reagents; open square denotes the absence of these components. "Pourable" and "Nonpourable" refer to the rheology in each regime. See text for additional details.

Table 3. Maximum loading of silicon carbide powders

\begin{tabular}{lcc} 
Powder & $\mathrm{pH}$ & $\begin{array}{c}\text { Maximum loading } \\
(\text { vol \%) }\end{array}$ \\
\hline & 10.7 to 13.0 & 47 to 53 \\
377 & 11.5 & 17 \\
377 & 13.0 & 23 \\
375 & 11.3 & 47 \\
375 & 12.0 & 39 \\
074 & 12.1 & 50 \\
074 & 12.8 & 50 \\
074 & 13.1 & 50 \\
\hline
\end{tabular}

${ }^{a}$ See Fig. 4. 
375 decreases with increasing $\mathrm{pH}$, a finding that is not readily understood at present. Finally, the maximum loading of 074 is independent of $\mathrm{pH}$ above 12.1 and resembles the behavior of B-10 given in Fig. 4.

\subsection{GELATION}

Results obtained in gelation experiments are presented in Table 4. As stated earlier, most experiments involved B-10, owing to its central role in the preliminary research.,

In the absence of $\mathrm{SiC}$, all conditions produce rigid gels. Yet, in the presence of $\mathrm{SiC}$, gelation does not always occur. Though it is known ${ }^{4}$ that differences exist in the minimum concentration of initiator required to induce gelation, the data in Table 4 are somewhat surprising. That is, virtually none of the suspensions gelled under conditions for which the concentration of initiator was 0.4 and $0.8 \mathrm{wt} \%$ levels originally deemed sufficient. ${ }^{3}$ This result may be a consequence of the presence of free carbon in the powders, as was its early interpretation. Still, the correlation between the carbon content and the lack of gelation is not high, though it is recognized that the free carbon may conitibute to the inhibition of gelation in a secondary fashion. This aspect will be discussed later.

The data in Table 4 demonstrate, however, that the important parameters are the suspension $\mathrm{pH}$, the concentration of the initiator, that of the crosslinking agent, and the available (total) surface area of $\mathrm{SiC}$ per unit volume of solution. The effect of $\mathrm{pH}$ is clearly seen from a comparison of the data gathered on $\mathrm{B}-10$ at $\mathrm{pH} 11.5$ and 12.1 when the concentrations of initiator and crosslinking agent are 0.8 and $1.0 \mathrm{wt} \%$, respectively. The lower $\mathrm{pH}$ conditions yield gels, whereas those at the higher ones do not, although the difference in $\mathrm{pH}$ is only 0.6 units. Interestingly, the two systems prepared with 074 exhibit similar pH-sensitive behavior.

Some of the suspensions prepared with B-10 at $\mathrm{pH} 11.5$ and 12.1 clearly demonstrate, moreover, that the ability of a system to gel depends on the concentrations of initiator and crosslinking agent. The critical concentration ranges over which gelation is sensitive are 0.44 to $1.02 \mathrm{wt} \%$ for the crosslinking agent at $\mathrm{pH} 11.5$ and 0.8 to $1.6 \mathrm{wt} \%$ for the initiator at pH 12.1.

Of particular pertinence to gelcasting as a viable fabrication technique is the fact that, according to Table 4, the minimum concentrations of initiator and crosslinking agent that promote gelation are also determined, at least in part, by the total particle surface area available to the solution. For instance, B-10 was found to require higher minimum concentrations of these reagents than was 074 . This finding is consistent with the much 


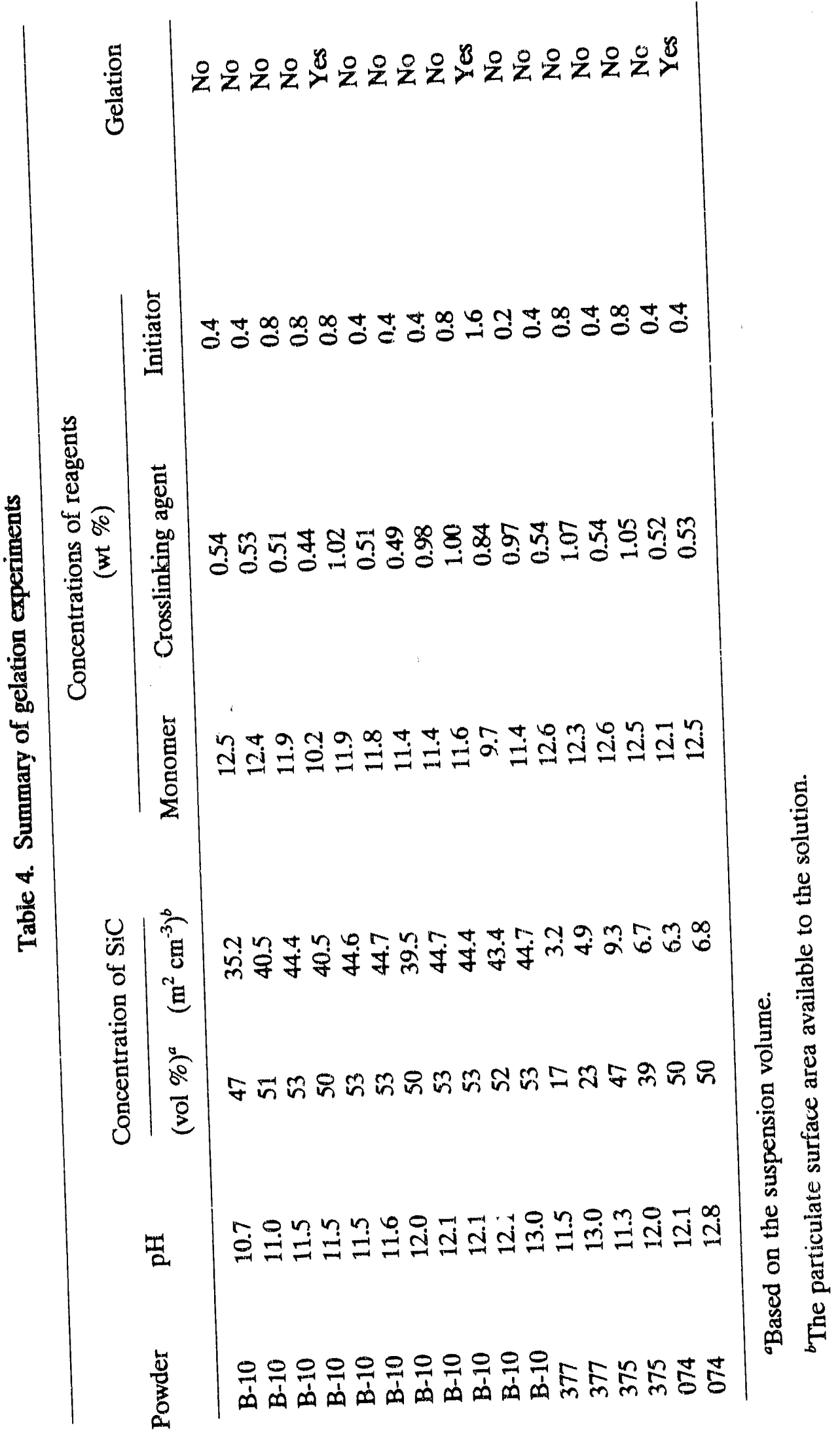


greater available surface area of $\sim 42 \mathrm{~m}^{2} \mathrm{~cm}^{-3}$ in the case of $\mathrm{B}-10$, as compared to $\sim 6.5 \mathrm{~m}^{2} \mathrm{~cm}^{-3}$ for 074. Unfortunately, time restraints did not permit the full investigation of 377 and 375 in this regard. However, note from Table 1 that the specific surface area of 074 is within a factor of $\sim 3$ to 5 of the values of 377 and 375 and approximately an order of magnitude less than that of B-10. This comparison suggests that the initiator and crosslinking agent may adsorb onto $\mathrm{SiC}$ particulates or onto free-carbon particulates. Such adsorption may be enhanced by the presence of free carbon either on the $\mathrm{SiC}$ surface or as separate particulates, perticularly if it has a graphitic-like surface structure.

\section{DISCUSSION}

\subsection{GENERAL SUSPENSION REQUIREMENTS}

The data presented herein indicate that the primary requirement for the preparation of suspensions with a high concentration of $\mathrm{SiC}$ is that the $\mathrm{pH}$ be sufficiently basic. Under these conditions, the surface charge of the powder generates an electrostatic repulsion that prevents van der Waals forces from stabilizing clusters and extensively grown agglomerates. lmportantly, the compositions investigated seem adequately pourable for gelcasting purposes. This quality implies that the viscosity and rheological yield (e.g., Bingham yield value) are sufficiently low for practical concerns. This $\mathrm{pH}$ control obviates the use of a dispersant in $\mathrm{SiC}$ systems and appears not to have been previously considered a viable option. ${ }^{1,3,4}$

\subsection{ROLE OF PARTICLE AND SUSPENSION PROPERTTES}

The $\mathrm{pH}$ of the suspension is central to the establishment of the surface charge that, in turn, (1) ensures the stability of a slurry, (2) reduces the sedimentation rate, and (3) maximizes the volume fraction on packing and the related maximum loading. These studies have shown that particle size can slightly affect the minimum $\mathrm{pH}$ at which a suspension is stable, but the effect is not large.

Fluidity was qualitatively assessed. This approach seems adequate for the present brief investigation. However, rheological measurements are needed to determine if obstacles exist regarding the flow of these suspensions and the stability of bubbles in specific fabrication procedures. De-airing procedures are required when rheological phenomena kinetically stabilize bubbles trapped on or between particles. ${ }^{\text {3a }}$ Yet, the maximum, useful concentration of $\mathrm{SiC}$ is not likely to differ significantly from those given in Fig. 4 and Table 3. 


\subsection{GELATION REQUIREMENTS}

The concentrations of the gelation reagents have been shown in the present study to be important considerations when comparing the behavior of suspensions prepared either under different $\mathrm{pH}$ conditions or with different powders. At the present time, adsorption of the initiator and crosslinking agent onto the solid is inferred. The adsorption of monomer is possible, in principle, ${ }^{11}$ though this consideration was not experimentally pursued. It is noteworthy that the conditions under which gelation does not occur may promote the polymerization of monomer, yielding essentially soluble, polymer molecules. These either are of too low molecular weight or possess an insufficient number of crosslinked sites to be macroscopically considered gels.

The available surface area seems the most critical parameter that can be easily characterized for purposes of estimating the minimum concentrations of the reagents that yield useful gels in the presence of SiC. Of course, the relative proportions of these components may also determine whether or not a specific combination suffices, but this effect is anticipated to be small.

\subsection{SUGGESTIONS FOR FUTURE WORK}

Reference 1 identifies future work that is pertinent to developing materials and processes for heat exchanger applications. Based on the present study, a systematic approach can be developed for those powder systems that resemble the ones investigated.

The proper characterization of the powders and the adjustments in processing, which must be made when adsorption phenomena occur, are of paramount importance for the development of flexible, suspension-based fabrication techniques that yield reliable ceramic components. Essential characterization involves (1) the measurement of electrophoretic mobility or other properties that directly relate to the minimum surface charge needed to stabilize the suspension, including the effects of washing the powder; (2) the determination of the specific surface area of the powder; and (3) the evaluation of the particle size distribution. The first set of data allows the prediction of suitable $\mathrm{pH}$ conditions and of the likelihood that dispersants may be required in the event that mobility is not sufficiently high, based on prior experience. The second type of data relates to the capacity of the available solid surface to accommodate the gelation reagents, if the interaction between them and the surface favors adsorption. The actual available surface area in a suspension provides an estimate of the 
maximum extent to which the reagents are "lost" to the surface and cannot, therefore, participate in the polymerization and gelation processes. Finally, the determination of the characteristics of the particle size distribution can be qualitatively used to assess whether or not additional procedures, such as fractionation by cize, would significantly improve the particle packing and the maximum loading. Future research in these areas would advance the present capabilities significantly.

\section{CONCLUSIONS}

The data presented herein and the colloidal aspects of dispersions discussed lead to the following conclusions regarding the preparation of concentrated, colloidally stable $\mathrm{SiC}$ suspensions.

1. The suspension $\mathrm{pH}$ is a critical parameter for determining the maximum concentration of $\mathrm{SiC}$; the difference between the processing $\mathrm{pH}$ and the isoelectric point $\left(\mathrm{pH}_{\mathrm{iep}}\right)$ determines the maximum loading of solids. The best conditions for gelcasting exist if $\mathrm{pH}>>\mathrm{pH}_{\mathrm{iep}}$; this situation occurs in the $\mathrm{pH}$ range exceeding $\sim 11$ for the powders examined $\left(\mathrm{pH}_{\mathrm{iep}}=3\right)$.

2. Dispersant is not needed to prepare $\mathrm{SiC}$ suspensions that are sufficiently concentrated $(\sim 50 \%)$ for gelcasting.

3. Generally, the maximum loading of $\mathrm{SiC}$ increases with $\mathrm{pH}$, asymptotically approaching the highest value for a givesi powder in the $\mathrm{pH}$ range, 11 to 13 .

4. The reasons why 377 behaves differently from the other powders are presently unclear.

5. Neglecting 377, whose behavior seems atypical, the role of particle size is understood in classical, colloidal terms; the minimum $\mathrm{pH}$ at which the highest maximum loading is achieved increases slightly with increasing particle size (i.e., with decreasing available surface area per unit volume of solution for a constant volume-based concentration of $\mathrm{SiC}$ ).

6. The presence of free carbon may inhibit gelation at low concentrations of the crosslinking agent and initiator. This effect appears to relate to the available surface area.

7. When free carbon is present in the powder, the crosslinking agent and initiator probably adsorb onto particulates, possibly onto the carbonaceous areas, but adsorption onto $\mathrm{SiC}$ must also be considered. 
8. Finally, TMAOH has been shown to be effective in circumventing the problems of bubbling and foaming that occur if ammonia is used to attain the basic $\mathrm{pH}$ conditions needed to disperse $\mathrm{SiC}$ at high concentrations.

\section{ACKNOWLEDGMENTS}

The author thanks C. G. Westmoreland for conducting the experiments and for many usefu. and insightful discussions; O. O. Omatete, T. N. Tiegs, and P. F. Becher for reviewing this report; A. C. Young for introducing him to gelcasting; and L. M. Evans for preparation of the draft and S. M. Wilson for preparation of the final report.

The author is grateful to M. A. Karnitz for providing support and guidance during this preliminary research. It is hoped that future work will build upon the elucidation of the critical factors for high SiC loading described herein.

\section{REFERENCES}

1. (a) J. S. Keed, Introduction to the Principles of Ceramic Processing, John Wiley \& Sons, New York, 1988.

(b) G. L. Messing, S. Hirano, and H. Hausaer, ed., Ceramic Powder Science, Ceramic Transactions, Vol. 12, American Ceramic Society, Westerville, Ohio, 1990.

2. A. C. Young, O. O. Omatete, M. A. Janney, and P. A. Menchhofer, "Gelcasting of Alumina," J. Am. Ceram. Soc. 74(3), 612-18 (1991).

3. (a) A. C. Young, letter report to M. A. Karnitz, Initial Investigation of Dispersion of SiC Powder in Aqueous Solution, March 26, 1990.

(b) E. Carlstrom, M. Persson, E. Bostedt, A. Kristoffersson, and R. Carlsson, "Slip Casting and Sintering of Silicon Carbide," pp. 175-84 in Silicon Carbide '87, Ceramic Transactions, Vol. 2, ed. J. D. Cawley and C. E. Semler, American Ceramic Society, Westerville, Ohio, 1989.

4. A. C. Young, private communications, August 9 and 13, 1990.

5. (a) Materials for High Performance Parts [data sheet], Hermann C. Starck, Berlin.

(b) Technical Representative, private communication, November 7, 1990.

6. HSC 375, 377 Silicon Carbide (Beta Phase) [product data sheet], Superior Graphite Co., Chicago, October 11, 1988. 
7. HSC 074, 075, 077 Silicor: Carbide (Beta Phase) [product data sheet], Superior Graphite Co., Chicago, September 18, 1989.

8. P. G. Stecher, ed., The Merck Index, 8th ed., Merck \& Co., Rahway, N. J., 1968, p. 1028.

9. P. K. Whitman and D. L. Feke, "Comparison of the Surface Charge Behavior of Commercial Silicon Nitride and Silicon Carbide Powders," J. Am. Ceram. Soc. 71(12), 1086-9.3 (1988).

10. M. J. Crimp, R. E. Johnson, J. W. Halloran, and D. L. Feke, "Colloidal Behavior of Silicon Carbide and Silicon Nitride," pp. 539-49 in Science of Ceramic Chemical Processing, ed. L. L. Hench and D. R. Ulrich, John Wiley \& Sons, New York, 1986.

11. O. O. Omatete, A. C. Young, and M. A. Janney, "Investigation of Dilute Gelcasting Alurnina Suspensions," pp. 537-44 in Ceramic Powder Science III, Ceramic Transactions, Vol. 12, ed. G. L. Messing, S. Hirano, and H. Hausaer, American Ceramic Society, Westerville, Ohio, 1990. 
ORNL/TM-11843

Distribution

Category UC-310

\section{INTERNAL DISTRIBUTION}

1-2. Central Research Library

3. Document Reference Section

4-5. Laboratory Records Department

6. Laboratory Records, ORNL-RC

7. ORNL Patent Section

8-12. M\&C Records Oftice

11. P. Angelini

12. R. L. Beatty

13. P. F. Becher

14-18. A. Bleier

19. W. D. Bond

20. R. A. Bradley

21. R. S. Carlsinith

22. N. C. Cole

23. D. F. Craig

24. L. L. Horton

25. M. A. Janney
26. D. R. Johnson

27-29. M. A. Karnitz

30. J. R. Keiser

31. J. O. Kiggans, Jr.

32. A.J. Moorhead

33. O. O. Omatete

34. S. Scott

35. J. O. Stiegler

36. T. N. Tiegs

37. P. T. Thornton

38. J. R. Weir

39. A. D. Brailisford (Consultant)

40. Y. A. Chang (Consultant)

41. H. W. Foglesong (Consultant)

42. J. J. Hren (Consultant)

43. M. L. Savitz (Consultant)

44. J. B. Wachtman (Consultant)

\section{EXTERNAL DISTRIBUTION}

45. AIRESEARCH MANUFACTURING COMPANY, 2525 W. 190th Street, Torrance, CA 90509

D. M. Kotchick

46-47. AMERCOM/ATLANTIC RESEARCH CORPORATTON, 8928 Fullbright Avenue, Chatsworth, GA 91311-6180

W. E. Beyermann

J. Bird

48. ARGONNE NATIONAL LABORATORY, 9700 S. Cass Avenue, Argonne, IL. 60.439-4815

T. J. Rabas 
49. AVCO RESEARCH LABORATORY, INC., 2385 Revere Beach Parkway, Everett, MA 02149

R. C. Diehl

50. BABCOCK AND WILCOX, R\&D DIV., 1562 Beeson Street, Alliance, OH 44601

C. L. DeBellis

51-52. BABCOCK AND WrLCOX, 3315 Old Forest Road, P.O. Box 10935, Lynchburg, VA $24506-0935$

E. Barringer

A. C. Rogers

53-54. BABCOCK AND WILCOX, P.O. Box 11165, Lynchburg, VA 24505

D. Hindman

W. Long

55. BABCOCK AND WILCOX, 1735 I Street, N.W., Suite 814, Washington, DC 20006

J. L. Lauderdale

56. BALTIMORE AIRCOIL COMPANY, P.O. Box 7322, Baltimore, MD 21227

K. K. Flamm

57. BLOOM ENGINEERING COMPANY, INC., Horning \& Curry Roads, Pittsburgh, PA 15236

W. P. Goodboy

58. BP AMERICA, 4440 Warrensyille Cenier Road, Cleveland, OH 44106

R. C. Ruhl

59. THE CARBORUNDUM COMPANY, P.O. Box 832, Niagara Falls, NY 14302

R. S. Storm

60. THE CARBORUNDUM COMPANY, P.O. Box 1054, Niagara Falls, NY 14302

M. C. Kerr 
51-62. THE CARBORUNDUM COMPANY, 31935 Aurora Road, Solon, OH 44139

B. D. Hudson

T. F. Ukolowicz

63. CHARLES RIVER ASSOCIATES, 200 Clarendon Street, Boston, MA 02116

E. Holdgraf

64. COLUMBIA GAS SYSTEM SERVICE CORPORATION, 1600 Dublin Road, Columbus, OH 43216-2318

D. L. Brooks

65. COMBUSTION ENGINEERING, INC., 1000 Prospect Hill Road, P.O. Box 500, Windsor, CT 06095-0500

W. R. Roczniak

66. CONCO SYSTEMS, INC., 135 Sylvan Street, Verona, PA 15147

G. E. Saxon

67. CONSOLIDATED NATURAL GAS, 11001 Cedar Avenue, Cleveland, OH 44106

J. Bjerklie

68. CONSULTANT, 1040 Scenic Drive, Knoxville, TN 37919

A. P. Fraas

69. COORS PORCELAIN COMPANY, 600 Ninth Street, Golden, CO 80501

R. Kleiner

70. CORTEST ENGINEERING SERVICES, INC., 20010 Century Boulevard,

Suite 102, Germantown, MD 20874

G. M. Ugiansky

71. DUPONT COMPANY, P.O. Box 6090, Newark, DE 19711

A. E. Jones

72. E. A. MUELLER, INC., 1401 S. Edgewood Street, Baltimore, MD 21227

C. J. Kovarik 
73. ECOLOGY \& ENVIRONMENT, INC., 1700 North Moore Street, Suite 1105, Arlington, VA 22209

J. E. Wilson

74. E. I. DUPONT, Maple Run Building, P.O. Box 80721, Wilmington, DE 19880-0721

K. G. White

75. ENERGY CONVERSION TECHNOLOGY, INC., 1700 North Highland Road, Pittsburgh, PA 15241

J. W. Seehausen

76. EOS TECHNOLOGIES, INC., 1601 N. Kent Street, Suite 1102, Arlington, VA 22209

J. H. Ward

77. ETHYL CORPORATION, 451 Florida, Baton Rouge, LA 70801

W. O. Muenchinger

78. FERRO CORPORATION, 661 Willet Road, Buffalo, NY 14218

J. F. Grant

79. FLUIDYNE ENGINEERING CORPORATION, 5900 Olson Memorial Highway, Minneapolis, MN 55422

D. DeCoursin

80-81. GAS RESEARCH INSTTTUTE, 8600 W. Bryn Mawr Avenue, Chicago, IL 60631

S. Freedman

M. A. Lukasiewicz

82-83. GTE PRODUCTS CORPORATION, Hawes Strcet Towanda, PA 18848
J. L. Ferri
J. Gonzales

84. HAGUE INTERNATIONAL, 3 Adam Street, South Portland, MA 04106

S. B. Young 
85. HEAT TRANSFER RESEARCH, INC., 1000 So. Fremont Avenue, Alhambra, CA 91802

G. Breber

86-88. IDAHO NATIONAL ENGINEERING LABORATORY, P.O. Box 1625, Idaho Falls, ID 83415

B. W. Brown

W. R. Lloyd

W. G. Reuter

89-90. IMO INDUSTRIES, INC., Front Street, Florence, NJ 08518

H. W. Braun

M. J. Lenhardt

91. INSTITUTE FOR DEFENSE ANALYSIS, 1801 North Beauregard Street, Alexandria, VA 22311

M. A. Rigdon

B. Rossing

92. LANXIDE CORPORATION, 1 Tralee Industrial Park, Newark, DE 19714-6077
A. W. Urquhart

B. Rossing

93. LOVELACE INHALATION TOXICOLOGY RESEARCH INSTITU'TE,

P.O. Box 5890, Albuquerque, NM 87185

N. F. Johnson

94. MAUMEE RESEARCH \& ENGINEERING, INC., 27457 Holiday Lane, Suite G, Perrysburg, OH 43551

F. G. Rinker

95. MCDANIEL, 510 Ninth Avenue, P.O. Box 560, Beaver Falls, PA 15010-0560

L. Treusch

96. THE M. W. KELLOGG COMPANY, Three Greenway Plaza, Houston, TX 77046-0395

D. L. Johnson 
97-98. NORTON COMPANY, Worcester, MA 01606

B. D. Foster

M. L. Torti

99. PAR ENTERPRISE, INC', 12601 Clifton Hunt Lane, Clifton, VA 22024

W. J. Rebello

100-101. PENNSYLVANIA STATE UNIVERSITY, 201 Steidle Building, University

Park, PA 16801

R. E. Tressler

R. L. Webb

102. POWER GENERATION CONSULTANTS, 1261 Post House Lane, Media,

PA 19063

M. DeCorso

103. PRESQUE ISLE ENGINEERING, 2046 N. M-30, P.O. Box 260, Sanford, MI 48657

R. G. Graham

104. PRINCETON ADVANCED TECHNOLOGY, INC., 56 Finley Road, Princeton, NJ 08540

H. A. Huckins

105. PURDUE UNIVERSITY, West Lafayette, IN 4790'7

R. Viskanta

106-107 RENSSELAER POLYTECHNIC INSTITUTE, 110 8th Sireet, Troy, NY $12180-3590$

A. E. Bergles

M. K. Jensen

108. SOLAR ENERGY RESEARCH INSTITUTE, 1617 Cole Boulevard, Golden, CO 80401

M. S. Bohn

109-111. SOLAR TURBINES INCORPORATED, P.O. Box 85376, San Diego,

CA $92138-5376$

B. Harkins

M. Van Roode

M. E. Ward 
112. SOUTHWESTERN ENGINEERING COMPANY, 5701 S. Eastern Avenue, Los Angeles, CA 90040

R. L. Ward

113-115. STONE \& WEBSTER ENGINEERING CORPORATION, 245 Summer Street, Boston, MA 02107

L. J. McDonough

R. A. Rosenberg

J. J. Williams

116. UNITED STATES ADVANCED CERAMICS ASSOCIATION, Suite 300, 1440 New York Avenue, NW, Washington, DC 20005

S. B. Hellem

117. U.S. DOE, IDAHO OPERATIONS OFFICE, 550 Second Street, Idaho Falls, ID 83401

G. R. Peterson

118-119. U.S. DOE, MORGANTOWN ENERGY TECHNOLOGY CENTER, P.O. Box 880, Morgantown, WV 26505

J. M. Hobday

H. A. Webb

120-121. U.S. DOE, DOE FIELD OFFICE, P.O. Box 2008, Building 4500N, MS-6269, Oak Ridge, TN 37831-6269

M. J. Rohr

Deputy Assistant Manager for Energy Research and Development

122-126. U.S. DOE, OFFICE OF INDUSTRIAL TECHNOLOGIES, 100 Independence Avenue, Forrestal Building, Washington, DC 20585

J. Eustis

T. J. Gross

W. P. Parks, Jr.

S. L. Richlen

A. J. Sireb

127. U.S. DOE, OFFICE OF FOSSIL ENERGY, Technical Coordinator, FE-14, B114 GTN, Washington, DC 20585

J. P. Carr 
128. U.S. DOE, PITTSBURGH ENERGY TECHNOLOGY CENTER, P.O. BOx 10940, Pittsburgh, PA 15236

J. D. Hickerson

129. U.S. DOE, ECUT/COMBUSTION TECHNOLOGY PROGRAM, CE-121, 1000 Independence Avenue, S.W., Washington, DC 2058.5

D. H. Knocbel

130-131. U.S. DOE, OFFICE OF TRANSPORTATION TECHNOLOGIES, CE-151, 1000 Independence Avenue, S.W., Washington, DC 20585

R. Schulz

T. Vojnovich

132-141. U.S. DOE, OFFICE OF SCIENTIFIC AND TECHNICAL INFORMATION, P.O. Box 62, Oak Ridge, TN 37831

For distribution by microfiche as shown in DOE/OSTI-4500,

Distribution Category UC-310 Industrial Programs (General) 

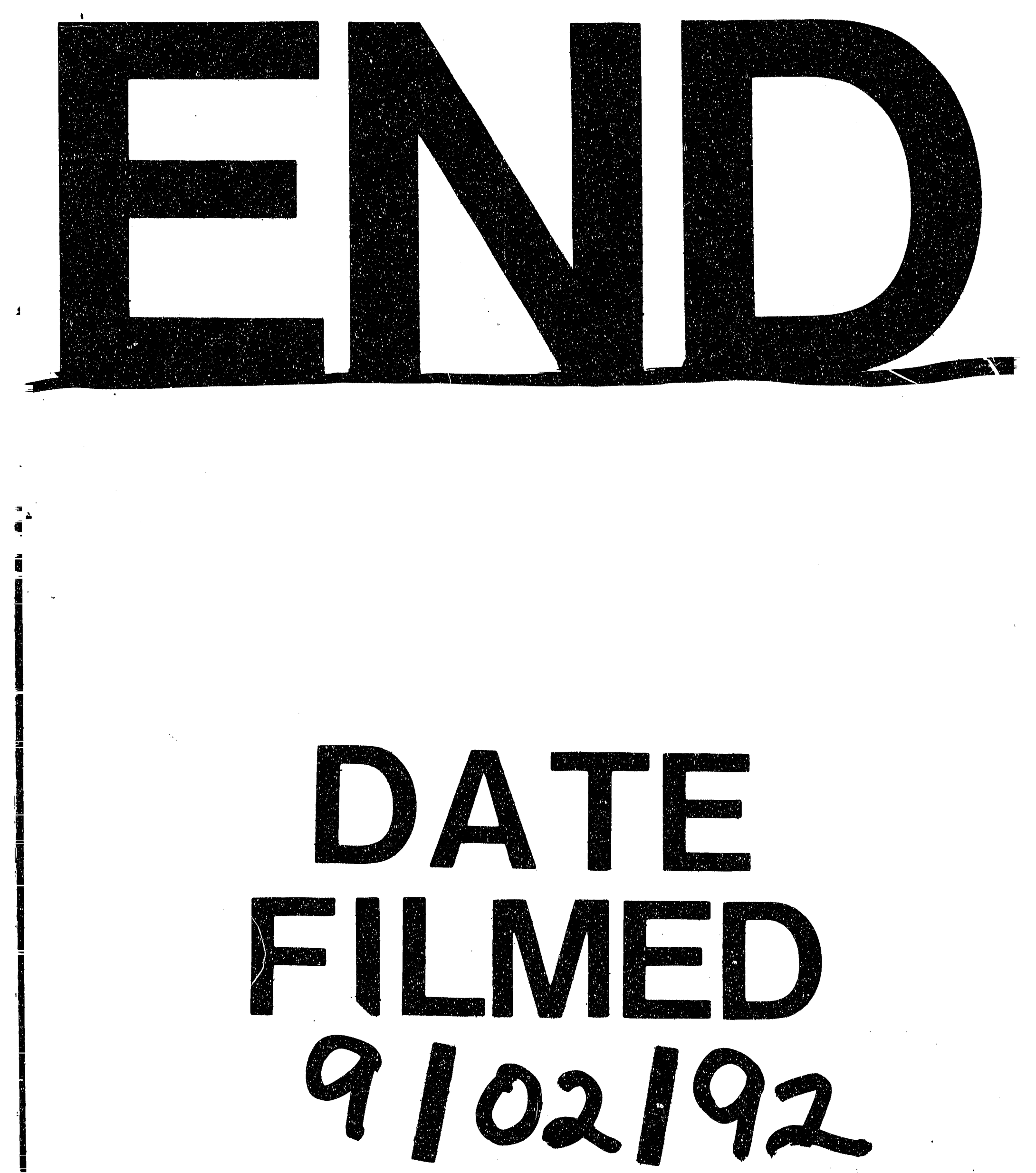


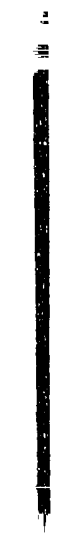

